\title{
Attention to the inheritance of traditional cultural spirit in ancient literature education
}

\author{
Huizhen SHEN \\ Pingdingshan Institute of Education \\ Pingdingshan Henan, 467000 China
}

\begin{abstract}
Chinese traditional culture is the crystallization of Chinese wisdom and spirit. Educating young students about traditional culture is an essential way of carrying forward and cultivate national spirits, as well as improving the quality of people of the nation. Ancient literature works not only indicates the instrumental feature of Chinese, but also condensed the essence of ancient people's sparkling thoughts. It is a significant carrier of excellent traditional cultural spirit Therefore, in middle school, an important term for maturity and formation of life values and world outlooks of teenagers, educating the outstanding traditional cultural spirit through teaching ancient literature is very necessary. However, known from current teaching practice, it is woeful that these precious wealth was wasted in the process of teaching. Teachers and students emphasis more on test abilities, and non-humanistic qualities, which cause the deficiencies in excellent traditional cultural spirit of some students. Of course, Chinese education may not shoulder the heavy responsibility of propagating the national spirit andimproving the quality of the nation alone, but it should always adhere to "spirit home".
\end{abstract}

Keywords- Ancient literature the traditional culture in works inheritance of spirits

\section{INTRODUCTION}

In perspective of the ancient literature education, this article focus on present situation that some middle school students lack traditional cultural spirit and then conduct a discussion on "how to inherit the excellent traditional culture spirit through ancient literature teaching" based on current version of high school language teaching textbook. First of all, this paper expounds the connotation of "the spirit of traditional culture", analyzes shared features of its essence and dross, and then proposes that it is important to guide students how to deal with the spirit of traditional culture correctly in the term of teaching. Then, the paper demonstrates the status that contemporary middle school student lack understanding of excellent traditional cultural spirit, and analyze the causes, among which particularly emphasized on the harm of lack excellent traditional cultural spirit for middle school students. Aimed at this situation, this paper emphasize on how great influence that teaching ancient literature works will do on cultural value, educational value and aesthetic value, as well as the significance that excellent traditional cultural has on heritage of spirit in the following sections. A profound analysis of the current situation that the impacts of ancient literature teaching on the excellent traditional culture and spiritual tradition have not been paid enough attention to is given in this paper. In addition, at the final part of the essay, a series of solutions are presented from four aspects: teaching methods, teachers, teaching materials, extracurricular activities in order to gain efficient results.

\section{CONTEMPORARY MIDDLE SCHOOL STUDENTS AND EXCELLENT TRADITIONAL CULTURE}

\section{A. The connotation of "the spirit of traditional culture"}

China is an ancient civilized country with a long history of 5,000 years. By 5000 years`sediment, Chinese culture gradually became broad and profound. Chinese classical literary such as the Tang and Song poetry, drama, painting, and calligraphy is admired all over the world; Chinese traditional costumes such as Hanfu clothing, Tang suits also deeply attract modern people; Chinese 5000 years history also has far-reaching significance in guiding us; Confucianism and Sun Tzu's art of war is even praised highly by contemporary business, culture field. Chinese culture has enough power to make both native and overseas glorious and proud. It is not only the symbol of the Chinese nation, but also the important strength of Chinese national cohesion. Although the concepts, thinking, behavior and lifestyles of modern Chinese are undergoing significant changes and Chinese culture is in a full range of transformation and development, this kind of transformation and development itself is under the basis of the traditional culture. Therefore, to explain the connotation of "the spirit of traditional Chinese culture", we should have an understanding of the Chinese traditional culture at first.

The spirit of traditional culture in our country has the essence as well as dross. We should draw upon its cream to its dregs, and inherit and promote the spirit of unity, unremitting self-improvement, social commitment, awareness within the outstanding national spirits, let these great spirits become the soul and source of our national cohesion ,the spiritual power of our national progress, and the national spiritual pillar and home.

\section{B. The current situation that contemporary students lack excellent traditional cultural spirits}

A lot of people have such a hallucination. they think that as long as the China and Chinese are still there, Mandarin still exists, Chinese knowledge and cultural heritage has not died out, it means Chinese traditional culture will still 
placidly survive, or even develop, whether pleasurable or bothersome for people, that is why we hear 'twenty-first Century will be the century for Chinese culture' and 'the process to build an open China still face the task of eradication of feudalism' those two different voices at the same time. "However, the problem now is, behind these two totally opposite arguments, namely, Chinese traditional culture alive, as well as almost disappeared. The mainstream of Chinese traditional culture is facing an unsustainable situation." Zhang Xianglong, a foreign philosophy and philosophy professor in Peking University, says in "the crisis of Chinese traditional culture".

The thesis aptly pointed out the current status of Chinese traditional culture, as well as the phenomenon that Chinese traditional culture are absent from contemporary middle school students. Those students, who present Chinese future, now have many cultural, spiritual problems.

\section{1) Values of contemporary middle school students}

Values of middle school students are their understandings and pursuits toward values and the value relations. It is the key factor that influence how they set goals, choose the way they behave and how they explain their behavior results. Guiding the students to establish correct values is the foundation and entry to promote the construction of the modern school student culture. For middle school students, who will soon become a main force of social construction, their present values are likely to influence their future, and even affect the future of Chinese

\section{2) Theaesthetic of contemporary middle school students}

Pursuing beauty is human nature, and high school students are no exceptions. In their study and life, they gradually formed their own aesthetic taste and the way to pursue beauty. The development of the economy provides people with the objective conditions to pursue beauty. It also help to meet the strong aspirations to chase beauty of middle school students in different extent at the same time. However, because of the special stage they are in, the influence that social aesthetic has on adolescent is especially prominent, so there are obvious weaknesses in their pursuit of beauty: they have a desire for beauty, but not good at identifying beauty, they tend to focus on physical beauty, but ignore inner beauty; they are more likely to admire popular c beauty, but forget the beauty of elegance and personality.

\section{3) Thelanguage habits of contemporary middle school students}

Ancient text dictations are never absent from junior and senior high school language examination, which are always full of hilarious answers. This phenomenon is not only a reflection of indifferent attitudes towards national languages of some middle school students, and their blindly chase on the popular "new things", but also a reflection of students` low accomplishments in ancient literary. Initially faced with funny language and "humor" answers, it is easy to laugh away. But, as a Chinese teacher, a traditional culture lover or a hot blooded patriot, it would cause an excruciating pain in the chest. What is more, the alarm would ring beside ears!Language is the root of a nation, the symbol of a nation, the dignity of a nation, the future of a nation. It is difficult to imagine what kind of future a nation will have without their own languages. Protecting our language, is to protect our own dignity. If language is lost, our souls will no longer exist. Therefore, for the excellent ancient literature, we should shoulder the responsibility of inheriting and passing.

\section{4) Contemporary middle students' attitudes toward traditional festivals}

The attitudes of contemporary middle school students towards Chinese traditional culture is changing from unknowing to disregarding. Take examples from their attitudes Towards Chinese traditional festival: Zhang Xianglong in one of his articles, "Chinese traditional cultural crisis", mentioned about: "official holiday can be viewed as a domestic language, national language." However, according to the report on people. com.cn, a large number of traditional festivals are in danger. Although we will still eat tangyuan at Lantern Festival and wrap up zongzi at the dragon boat festival, but except the form of eating is not changed, the contents of festival culture is increasingly withered. People`s participation enthusiasm decrease constantly and almost exists in name only. While another indisputable fact is that some exotic holiday is becoming more and more popular within young people, which in turn make the desertion of traditional festivals even more obvious.

\section{The causes and negative impacts of lacking excellent traditional culturalspirits for contemporary middle school students}

According to psychology, within people's psychological development conditions, the genetic quality is the premise of biological development, while what determine human development are the environment, education power and individual psychological motivation. Therefore, the present situation that students lack of traditional cultural spirits is mainly the outcome of the environment, education and individual choice.

\section{1) The impacts of foreign culture}

In a number of investigations in different regions, contemporary young people demonstrated indifferences against the traditional culture and keen and obsession on American mass culture. The Popularization of internet and the change of information transformation mode, make foreign culture ideology unimpeded, and quickly and effectively assimilate Chinese youth. Subsequently, there will be an inevitably upward tendency of negative effects. For middle school students, what they see are numerous things in foreign culture, what they hear are a various kinds of information, what they feel are unhealthy trends in society, 
these negative effects will offset the positive education of family and school.

\section{2) The impacts of society and families}

Middle school students are in the psychological weaning period. On the one hand, the rapid development of the body enhance their strength and germinate their sexual consciousness, they look forward to being part of the adult world, and like to imitate adult actions. On the other hand, the psychological development fall behind, they are good at imitating but know nothing about discriminating. They have strong curiosity, imagination and imitation abilities, which make them extremely vulnerable to be influenced by adverse effects of social culture.

China is now atpreliminary stage of market economy in which some values of the planned economy has been destroyed, but the concepts and values of market economy has not been fully established. There is a rising tendency to for the society to pursue nothing but profits. When all of these reflects on the contemporary culture, that high school students will easily impacted. In addition, the money worship, feudal superstition, denial of the advantages of education, virtual network culture experience also have a great negative impact on students.

Healthy family environment can guide their children to the treat and select the mass culture correctly, as well as the form good qualities; while bad family environment will "expand" the negative social effects. because of various reasons such as Chinese large population, there are few systematic, professional guidance and education for the parents, so although the "great importance of family education" problem has also become a hot topic in China, however, many families in China still have not been out of misunderstandings of education, which affects improvement of the quality of the young people even today.

3) The deviation between actual education activities and the educational goals

The school is the main place for educational and cultural transmission. Although the whole society is appealing for quality-oriented education and moral education, the actual situation is not satisfying. Under the one-sided pursuit of enrollment rate, in order to have a greater chance of survival, schools put the pressure on teachers, and teachers work object is students, which makes the actual school education deviated from the goal of education.

At the same time, many schools value science more than art and lay more press on score than abilities in the real educational activities, therefore it mislead students to focus only on the exam knowledge and ignore the improvement of quality, which restricts the development of students personality and the pioneering spirits of innovation. Secondly, education method is not appropriate. Instead of applying in accordance with their aptitude and personalities, parental education, cramming method of teaching dominates in education field, which lead to the boredom towards study even truancy and in turn pursue all sorts of comforts and repose in society; Finally, the extracurricular activities are formalized. Many schools, will reduce or even cancel the extracurricular activities time in order to guarantee more learning time. In the so-called "second class" for the development of students' interest has become a marine of exercises. Tedious learning life cannot meet the growing knowledge desire of students so they set their sights on society to seek compensation.

4) The tendency of students individual sense

During an individual life, psychology is continuously developing. Generally speaking, from birth to mature period, the total development trend of psychological is from simple to complex, from junior to senior, from chaos to the rising process of differentiation.

\section{THE SIGNIFICANCE AND CURRENT STATUS THAT} ANCIENT LITERATURE TEACHING HAS ON THE INHERITANCE OF EXCELLENT TRADITIONAL CULTURE AND SPIRITUAL TRADITION

\section{A. The significance that ancient literature teaching has on the inheritance of excellent traditional culture and spiritual tradition}

Chinese textbooks and culture are inextricably linked. On the one hand, Chinese textbooks originate, grow and develop from the culture. Culture, as the matrix of Chinese textbooks, decides the cultural character of Chinese teaching materials, and lay the fundamental construction, logical concept and category of the source for Chinese teaching material. Setting aside culture, language teaching has become passive water. On the other hand, Chinese textbooks, which scour and introspect culture, is an important means and media of the development of culture. It add value to culture and help culture to realize the innovation, and finally generate and compose culture. Aside from Chinese textbooks, cultural heritage, update and educational significance will face the predicament and crisis

Chinese traditional culture and language teaching have profound origins, especially the ancient literary works in middle school Chinese textbooks, contains the spirit of traditional Chinese culture is extremely rich content. These works not only reflect the language tool, more condensed the ancient sparkling thought essence, such as patriotism, collectivism lofty emotion, and hardworking, honest and other traditional virtue, strong, courageous and excellent quality, is the important carrier of Chinese traditional culture spirit.

\section{B. Current situation of the inheritance of traditional cultural spirit in ancient literature works education}

Chinese ancient literature is the rich heritage formed by thousands of years of accumulation. It is rich, colorful, multitude, profoundly and vividly embodying the spirit of traditional culture. Therefore, only by thoroughly probing into ancient literature, can the students understand the implication of the Chinese spirit in the process of learning excellent works of ancient Chinese, as well as lay the foundation for the formation of certain traditional cultural spirit. Furthermore, it will benefit student to know how to learn from the perspectives of historical development, absorb national wisdom from ancient literature; scan works with modern ideas, and evaluate the positive significance and historical limitations. 
The present situation of the inheritance of traditional cultural spirit in ancient literature works educationis not optimistic. It require all the Chinese educators to work together to explore a way that get Chinese education out of dilemma.

\section{SOLUTIONS TO THE INHERITANCE OF TRADITIONAL CULTURAL SPIRIT IN ANCIENT LITERATURE WORKS EDUCATION}

\section{A. Textbooks aspect}

In order to meet the reform of fundamental education curriculum, the new Chinese textbook are compiled after the implement of new curriculum. Taking the version of high school language textbook as an example, the editor struggle to demonstrate the concept of the national senior high school curriculum reform, and enhancing the teaching objectives and requirements. This set of textbooks in aspects like the form structure, layout, and the ideological connotation all have great breakthrough, it can be said to be a good set of teaching materials since the founding of new China. Many experts and teachers all think highly of that. But nothing is perfect.

\section{B. Teachers' aspect}

As The introduction of new curriculums, many Chinese teachers re-examine the process teaching. During teaching Chinese, they let students learn autonomously and experience the text by themselves, which will give them the feelings about life and societies. In another word, the subjectivity of students has been clearly defined. However, the teaching practice also tells us, in the process of teaching, without the guidance of teachers, students' subjectivities are impossible to have practical meanings. That is to say, only by active guidance of teachers can the students learn passionately in the process, which will enable students to accurately acquire knowledge and improve the comprehensive ability, as well as help them become the main learning objectives. Therefore, the author thinks that in the ancient literature works teaching, the leading role of teachers is crucial when stimulating students interests in learning. Teachers should play a leading role in teaching, which basically means that teachers should have correct understandings of some problems and improve themselves in literature and moral accomplishments.

\section{Teaching aspect}

The process of teaching Chinese is also a process for teachers and students to communicate about their understanding of the textbooks using Chinese language. To stimulate the vitality of classes and improve the efficiency of Chinese classes, optimizing the teaching process will be an effective way. As discussed in the previous sections, there are many problems existing in our ancient literature teaching, and these problems are the cruxes that spirits of traditional culture cannot be delivered by the ancient literature works teaching. So figuring out how to carry on the classical literature teaching process and how to effectively inherit the spirit of traditional culture seems particularly important.

\section{CONCLUSION}

As Daudet said, "When a nation becomes slaves, as long as it clings to its language, it is like holding the key to the prison". For the continuation of a nation, the most important continuation is national spirit. Basically, if a nation does not have or hold onto their own traditional culture and national spirit, it cannot be called a true nation that can stand independently in the world, but an extinct nation. Those who do not have their own national spiritual symbol is simply just a group of people surviving in this world, it cannot be called a nation. Therefore, the continuation of the traditional ethnic culture is very crucial for the survival and development of a nation.

\section{References}

[1] 2003regular secondary school Chinese language course standards (test), Chinese ministry of education, 2003

[2] Gu Huangchu, Gu zhenbiao, chinese language courses and textbook, Beijing, social and science literature press, 2001 edition

[3] Zhou Qingyuan, the teaching theory of middle school Chinese, Changsha, Hunan education press, 1992 Edition

[4] Zhou Qingyuan, the psychological Research of middle school Chinese education, Changsha, Hunan education press, 1999 Edition

[5] Zhou Qingyuan, Research introducion to Chinese education, Changsha, Hunan education press, 2003 Edition

[6] Chen Da, the theory of life eduction, Shenyang, Liaoning education press, 1998 Edition

[7] Chen Da, the theory of Chinese subject, Shenyang, Liaoning education press, 1998 Edition

[8] Chen $\mathrm{Da}$, analysis of teaching goals, Changsha, Hunan education press, 2000 Edition

[9] Zhang Liangtian, analysis of teaching methods, Changsha, Hunan education press, 1999 Edition

[10] Zhou Qingyuan Chen Dayu Zhang Liangtian, Brief chinese teaching for middle school, Beijing, Chinese People's Public Security University press, 1997 Edition

[11] "Classroom teaching art" (Editorial Department of Chinese Learning Series), Shanghai, Shanghai Education Press, 2000 Edition

[12] I Rao Teng, "Chinese education exploration", Beijing, Capital Normal University press, 2000 Edition

[13] "the teachers in the new century literacy topics", Changchun, Northeast Normal University press, 2003 Edition

[14] Li Zonggui, "Introduction to Chinese culture", Guangzhou: Zhongshan University press, 1988 edition,

[15] Zhu Guangqian, " Brief discussion about aesthetic", Beijing, Beijing University Press, 2004 Edition 